\title{
Simulation of gas explosions
}

\author{
BJØRN H. HJERTAGER†
}

Keywords: Fluid dynamics, combustion, turbulence.

Gas explosion hazard assessments in flammable gas handling operations both offshore and onshore are crucial in order to obtain an acceptable level of safety. In order to perform such assessments good predictive tools are needed, which take account of the relevant parameters, such as geometrical design variables and gas cloud type and distribution. A theoretical simulation model must therefore be tested against sufficient experimental evidence prior to becoming a useful tool. The experimental data should include both variations in geometry and gas cloud composition and the model should give reasonable predictions without use of geometry or case dependent constants.

Numerical simulation methods capable of predicting flame and pressure development in turbulent gas explosions are presented. Special attention is given to methods which adopt the $k$-epsilon model of turbulence and the eddy-dissipation model of turbulent combustion.

Several verification calculations are presented, which include a variety of geometrical layouts as well as a range of different fuel-air mixtures. Comparisons between simulated and measured explosion data are in general in good agreement.

\section{Introduction}

\subsection{The problem}

Gas explosion hazard assessments in flammable gas handling operations are crucial in obtaining an acceptable safety. In order to perform such assessments good predictive tools are needed, which take account of the relevant parameters, such as geometrical design variables and gas cloud distribution. A theoretical model must therefore be tested against sufficient experimental evidence prior to becoming a useful tool. The experimental data should include both variations in geometry and gas cloud composition and the model should give reasonable predictions without use of geometry or case dependent constants.

\subsection{Relevant works}

It has in the past been usual to predict the flame and pressure development in vented volumes by modeling the burning velocity of the propagating flame. This may be successful if we have a simple mode of flame propagation such as axial, cylindrical or spherical propagation in volumes without obstructions in the flow. If these are

Received 1 August 1989.

† Chr. Michelsen Institute, Dept. of Science and Technology, N-5036 Fantoft, Bergen, Norway; present address: Telemark Institute of Technology (SIT), TMIH, Kjølnes, N-3900 Porsgrunn, Norway.

This paper was presented at SIMS '89 (Scandinavian Simulation Society), 31st Annual Meeting, Bergen, Norway, May 31-June 2, 1989. 
present, however, it is almost impossible to track the flame front throughout complex geometries. It has been apparent that in these situations it is more useful to model the propagation by calculating the rate of fuel combustion at different positions in the volume. It is also important to have a model which is able both to model subsonic and supersonic flame propagation to enable a true prediction of what can happen in an accident scenario. One such model which in principle meets all these needs has been proposed by Hjertager $(1982 \mathrm{a}, \mathrm{b})$ and Bakke and Hjertager $(1986,1987)$. The model has been tested against experimental data from various homogeneous stoichiometric fuelair mixtures in both large-scale and small-scale geometries. Similar models for gas explosion propagation have subsequently also been proposed by Kjäldman and Huhtanen (1986), Marx, Lee and Cummings (1985) and Martin (1986).

All the above models are similar in nature. They use finite-domain approximations to the governing equations. Turbulence influences are taken account of by the $k-\varepsilon$ model (Launder and Spalding 1974), and the rate of combustion is modeled by variants of the eddy-dissipation concepts (Magnussen and Hjertager, 1976). The Bakke and Hjertager models (Hjertager 1982a,b, Bakke and Hjertager 1986, 1987) are incorporated in a computer code series named FLACS (FLame ACceleration Simulator). Two different solution methods are included, namely the SIMPLE technique of Patankar and Spalding (1972) and the ICE technique of Cloutman, Hirt and Romero (1976). The model of Kjäldman and Huhtanen (1986) uses the general PHOENICS computer code (Spalding 1981) which also uses a variant of the SIMPLE solution technique (Patankar and Spalding 1972). The model of Marx, Lee and Cummings 1985) uses the CONCHAS-SPRAY computer code (Cloutman, Dukowicz, Ramshaw and Amsden 1982) which embodies the ICE solution method. Finally, the model of Martin (1986) which is embodied in a computer code named FLARE uses the flux-corrected transport (FCT) (Boris and Book 1973) solution strategy.

\subsection{Objectives}

This paper will review the FLACS simulation model, show some validation calculations and present some predicted scaling characteristics.

\section{Governing equations}

\subsection{Mass and momentum}

The problem of turbulent explosion can be handled by solving for the time evolution of time mean values of the dependent quantities in the domain of interest. The time mean of a variable varying with time, $t$, may be expressed as

$$
\phi(t)=\frac{1}{T} \int_{t}^{t+T} \hat{\phi}(t+\tau) d \tau
$$

where $\phi(t)$ is the time mean value of the instantaneous value $\hat{\phi}(t)$ averaged over the time interval $T, T$ must satisfy two competing demands. Firstly, it must be small enough not to smear out the sought time dependence of the system under consideration. Secondly, it must be large enough to be able to produce sufficient information to enable relevant time mean values in the interval. This means that time mean values of both the relevant quantities and their second order correlations must be obtainable in the time interval $T$. This is often possible since conversely, turbulence has higher frequencies than the 
large scale motion which generates turbulence. The equation of motion and energy can thus be expressed in tensor notation as

$$
\begin{gathered}
\frac{\partial \rho}{\partial t}+\frac{\partial}{\partial x_{i}}\left(\rho U_{i}\right)=0 \\
\frac{\partial}{\partial t}\left(\rho U_{i}\right)+\frac{\partial}{\partial x_{j}}\left(\rho U_{j} U_{i}\right)=-\frac{\partial p}{\partial x_{i}}+\frac{\partial}{\partial x_{j}}\left(\sigma_{i j}\right) \\
\frac{\partial}{\partial t}(\rho h)+\frac{\partial}{\partial x_{j}}\left(\rho U_{j} h\right)=-\frac{\partial}{\partial x_{j}}\left(J_{h, j}\right)+\frac{D p}{D t}+S_{h}
\end{gathered}
$$

Here $U_{i}$ is the velocity component in the $x_{i}$ coordinate direction; $p$ is the pressure; $\rho$ is the density; $h$ is the enthalpy and $\sigma_{i j}$ and $J_{h, j}$ are the fluxes of momentum and energy.

\subsection{Chemical species}

The combustion is treated as a single step irreversible reaction with finite reaction rate between fuel and oxidant. Hence, the reaction scheme may be written as

$$
1 \mathrm{~kg} \text { fuel }+s \mathrm{~kg} \text { oxygen } \rightarrow(1+s) \mathrm{kg} \text { products }
$$

Here $s$ is the stoichiometric oxygen requirement to burn $1 \mathrm{~kg}$ of fuel. This simple reaction scheme results in mixture composition being determined by solving for only two variables, namely mass fraction of fuel, $m_{f w}$, and the mixture fraction, $f$

$$
\begin{gathered}
\frac{\partial}{\partial t}\left(\rho m_{f u}\right)+\frac{\partial}{\partial x_{j}}\left(\rho U_{j} m_{f u}\right)=-\frac{\partial}{\partial x_{j}}\left(J_{f u, j}\right)+R_{f u} \\
\frac{\partial}{\partial t}(\rho f)+\frac{\partial}{\partial x_{j}}\left(\rho U_{j} f\right)=-\frac{\partial}{\partial x_{j}}\left(J_{f, j}\right)
\end{gathered}
$$

Here $R_{f u}$ is the time mean rate of combustion of fuel, whereas $J_{f u, j}$ and $J_{f, j}$ are the diffusive fluxes in the $x_{j}$ direction. The basis for this to be valid is that the Schmidt numbers are equal for all species, an approximation which is often found in turbulent flows.

The mixture fraction is defined as

$$
f=\frac{\beta-\beta_{\infty}}{\beta_{0}-\beta_{\infty}}
$$

where $\beta$ is a conserved combined variable of, for example, mass fraction of fuel, $m_{f u}$ and mass fraction of oxygen, $m_{\mathrm{o}_{2}}$, expressed as:

$$
\beta=m_{f u}-m_{\mathbf{o}_{2}} / s
$$

$\beta_{0}$ is the value of $\beta$ at a fuel rich reference point, for example a fuel leakage point in the domain, and $\beta_{\infty}$ is the value of $\beta$ at an oxidant rich reference point, for example the ambient air condition. For a homogeneous premixed system the mixture fraction will be constant in the domain of interest and consequently only the $m_{f u}$ equation needs to be solved. 


\section{Turbulence and combustion models}

\subsection{General}

To solve the governing equations (2), (3), (4), (6) and (7) given above the fluxes, $J_{\phi, j}$, and the rate of combustion $R_{f w}$, have to be specified together with relevant boundary and initial conditions. Both the fluxes and the combustion rate are time mean averaged values of fluctuating quantities. The fluxes can, for a general scalar variable $\phi$, and a velocity component $U_{j}$, be expressed

$$
J_{\phi, j}=-\rho \overline{u_{j} \varphi}
$$

and

$$
\sigma_{i j}=-\rho \overline{u_{i} u_{j}}
$$

where $u_{i}$ and $\varphi$ are the instantaneous fluctuations around the time mean values $U_{j}$ and $\phi$, respectively. The overbar indicates time mean value over the time interval $T$ as defined in expression (1). When specifying the correlations given in (10) and (11) it is usual to relate these to the product of time mean gradients of the relevant variables and an effective turbulent transport coefficient. For a general scalar variable $\phi$ and a velocity component $U_{j}$ the relations are:

$$
J_{\phi, j}=-\frac{\mu_{\mathrm{cff}}}{\sigma_{\phi}} \frac{\partial \phi}{\partial x_{j}}
$$

and

$$
\sigma_{i j}=\mu_{\mathrm{eff}}\left(\frac{\partial U_{i}}{\partial x_{j}}+\frac{\partial U_{j}}{\partial x_{i}}\right)-\frac{2}{3} \delta_{i j}\left(\rho k+\mu_{\mathrm{eff}} \frac{\partial U_{k}}{\partial x_{k}}\right)
$$

respectively.

Here $\delta_{i j}=1$ if $i=j$ and $\delta_{i j}=0$ if $i \neq j$. An effective turbulence viscosity $\mu_{\text {eff }}$ and the kinetic energy of turbulence have been introduced in the above expressions, together with an effective Prandt1/Schmidt number $\sigma_{\phi}$. The kinetic energy of turbulence, $k$, is related to the fluctuating turbulence velocity components in the three coordinate directions as

$$
k=\frac{1}{2}\left(\overline{u_{1}^{2}}+\overline{u_{2}^{2}}+\overline{u_{3}^{2}}\right)
$$

The effective turbulence viscosity is given by the two turbulence parameters, the isotropic turbulence velocity $u_{t}$ and a length scale, $l$, as:

$$
\mu_{\text {eff }}=\mu_{l}+\rho u_{t} l
$$

$\mu_{l}$ is the molecular viscosity. The determination of the turbulence velocity and length scale is done by use of a turbulence model.

\subsection{Two-parameter turbulence model}

The determination of $u_{t}$ and $l$ are done by application of the so-called $k-\varepsilon$ model of turbulence (Launder and Spaulding 1974). The turbulence velocity is related to the kinetic energy of turbulence, $k$, as:

$$
u_{t}=\left(\frac{2}{3} k\right)^{1 / 2}
$$


and the length scale, $l$, is related to the kinetic energy of turbulence, $k$ and its rate of dissipation, $\varepsilon$, as:

$$
l \sim \frac{k^{3 / 2}}{\varepsilon}
$$

Inserting (16) and (17) into expression (15) give as result:

$$
\mu_{\mathrm{eff}}=\mu_{l}+C_{D} \rho \frac{k^{2}}{\varepsilon}
$$

$C_{D}$ is a constant taken to be 0.09 (Launder and Spaulding 1974). The conservation equations that determine the distribution of $k$ and $\varepsilon$ read

$$
\begin{gathered}
\frac{\partial \rho k}{\partial t}+\frac{\partial}{\partial x_{j}}\left(\rho U_{j} k\right)=\frac{\partial}{\partial x_{j}}\left(\frac{\mu_{\mathrm{eff}}}{\sigma_{k}} \frac{\partial k}{\partial x_{j}}\right)+G-\rho \varepsilon \\
\frac{\partial \rho \varepsilon}{\partial t}+\frac{\partial}{\partial x_{j}}\left(\rho U_{j} \varepsilon\right)=\frac{\partial}{\partial x_{j}}\left(\frac{\mu_{\mathrm{eff}}}{\sigma_{\varepsilon}} \frac{\partial \varepsilon}{\partial x_{j}}\right)+C_{1} \frac{\varepsilon}{k} G-C_{2} \rho \frac{\varepsilon^{2}}{k}
\end{gathered}
$$

The two new constants appearing above $C_{1}$ and $C_{2}$, are given the values 1.44 and 1.79 , respectively (Launder and Spaulding 1974). The Schmidt numbers $\sigma_{k}$ and $\sigma_{\varepsilon}$ are given the values $1 \cdot 0$ and $1 \cdot 3$, respectively, whereas the other Schmidt/Prandtl numbers are put equal to $0 \cdot 7$. The generation rate of turbulence is given by

$$
G=\sigma_{i j} \frac{\partial U_{j}}{\partial x_{i}}
$$

These production rate terms take account of turbulence produced by "shear and compression/expansion. If buoyancy production or Taylor-Rayleigh instability production is important additional terms may be added.

\subsection{Rate of combustion}

The rate of combustion may be modeled according to the 'eddy-dissipation' concept by Magnussen and Hjertager (1976) with the ignition/extinction modification introduced by Hjertager (1982 b).

Two time scales are defined, namely the turbulent eddy mixing time scale, $\tau_{e}=k / \varepsilon$, and the chemical time scale

$$
\tau_{c h}=A_{c h} \exp (E / R T) \cdot\left(\rho m_{f u}\right)^{a}\left(\rho m_{\mathrm{o}_{2}}\right)^{b}
$$

Also, an ignition/extinction criteria is defined when the two time scales are in a certain ratio, namely $\left(\tau_{c h} / \tau_{e}\right)^{*}=D_{i e}$. The rate of combustion is thus calculated as

$$
\left.\begin{array}{l}
R_{f u}=0 \text { when } \tau_{c h} / \tau_{e}>D_{i e} \\
R_{f u}=-A / \tau_{e} \rho m_{\lim } \text { when } \tau_{c h} / \tau_{e}<D_{i e}
\end{array}\right\}
$$

where $m_{\lim }$ is the smallest of the three mass fractions, namely fuel, $m_{f u}$, oxygen $m_{\mathbf{o}_{2}} / s$ or mass fraction of fuel already burnt, $m_{f u, b}$. The constants $A$ and $D_{i e}$ are given the values 16 , and 1000 , respectively. 


\section{Modeling of complex geometries}

Many geometries found in industrial practice may contain a lot of geometrical details which can influence the process to be simulated. Examples of such geometries are heat exchangers with thousands of tubes and several baffles, and regenerators with a lot of internal heat absorbing obstructions etc. In the present context the geometries found inside modules on offshore oil and gas producing platforms and geometries found in refineries constitute relevant examples of the complex geometries at hand. There are at least two routes for describing such complex geometries. First, we may choose to model every detail by use of very fine geometrical resolution, or secondly we may describe the geometry by use of some suitable bulk parameters. Detailed description will always need large computer resources both with regard to memory and calculation speed. It is not feasible with present or even with future computers to implement the detailed method for solving such complex problems. We are therefore forced to use the second line of approach, which incorporates the porosity/distributed resistance formulation of the governing equations. This method was proposed by Patankar and Spalding (1974) and has been applied to analysis of heat exchangers, regenerators and nuclear reactors. Sha, Yang, Kao and Cho (1982) have extended the method to include advanced turbulence modeling.

The presence of geometrical details modifies the governing equations in two ways. First, only part of the total volume is available to flow and secondly solid objects offer additional resistance to flow and additional mixing in the flow. The modified equations for use in high density geometries may be expressed by

$$
\frac{\partial}{\partial t}\left(\beta_{v} \rho \phi\right)+\frac{\partial}{\partial x_{i}}\left(\beta_{i} \rho U_{i} \phi\right)=\frac{\partial}{\partial x_{i}}\left[\beta_{i} \Gamma \frac{\partial \phi}{\partial x_{i}}\right]+\beta_{v}\left(S_{\phi}+R_{\phi}\right)
$$

Here $\phi$ denotes a general variable. $\beta_{v}$ is the volume fraction occupied by the fluid, $\beta_{i}$ is the area fraction available for flow in the $x_{i}$-direction and $R_{\phi}$ is the additional resistance or additional mixing or heat transfer caused by solid obstructions in the flow. All the volume/area fractions (porosities) may take values between $0 \cdot 0$, completely blocked, or $1 \cdot 0$, completely open. Some $R_{\phi}$ functions may be found in a report by Sha and Launder (1979). These functions depend on parameters like velocity, porosity, typical dimension, pitch between obstacles, obstacle shape and orientation.

\section{Solution procedures}

It is noted that all conservation equations mentioned above can be written in the following general form. (All porosities are set equal to unity for clarity):

$$
\begin{gathered}
\frac{\partial}{\partial t}(\rho \phi)+\frac{\partial}{\partial x_{j}}\left(\rho U_{j} \phi\right)=\frac{\partial}{\partial x_{j}}\left(\Gamma_{\phi} \frac{\partial \phi}{\partial x_{j}}\right)+S_{\phi} ; \Gamma_{\phi}=\frac{\mu_{\mathrm{eff}}}{\sigma_{\phi}} \\
\text { I }
\end{gathered}
$$

This means, equations with four distinct terms, namely: I transient, II convection, III diffusion and IV source terms. A summary of all the equations needed for a typical calculation of flows with chemical reaction are given in table 1.

Solutions of these equations are performed by finite-domain methods. Details of the computation methods are given by Hjertager (1982) and Bakke and Hjertager (1987). 


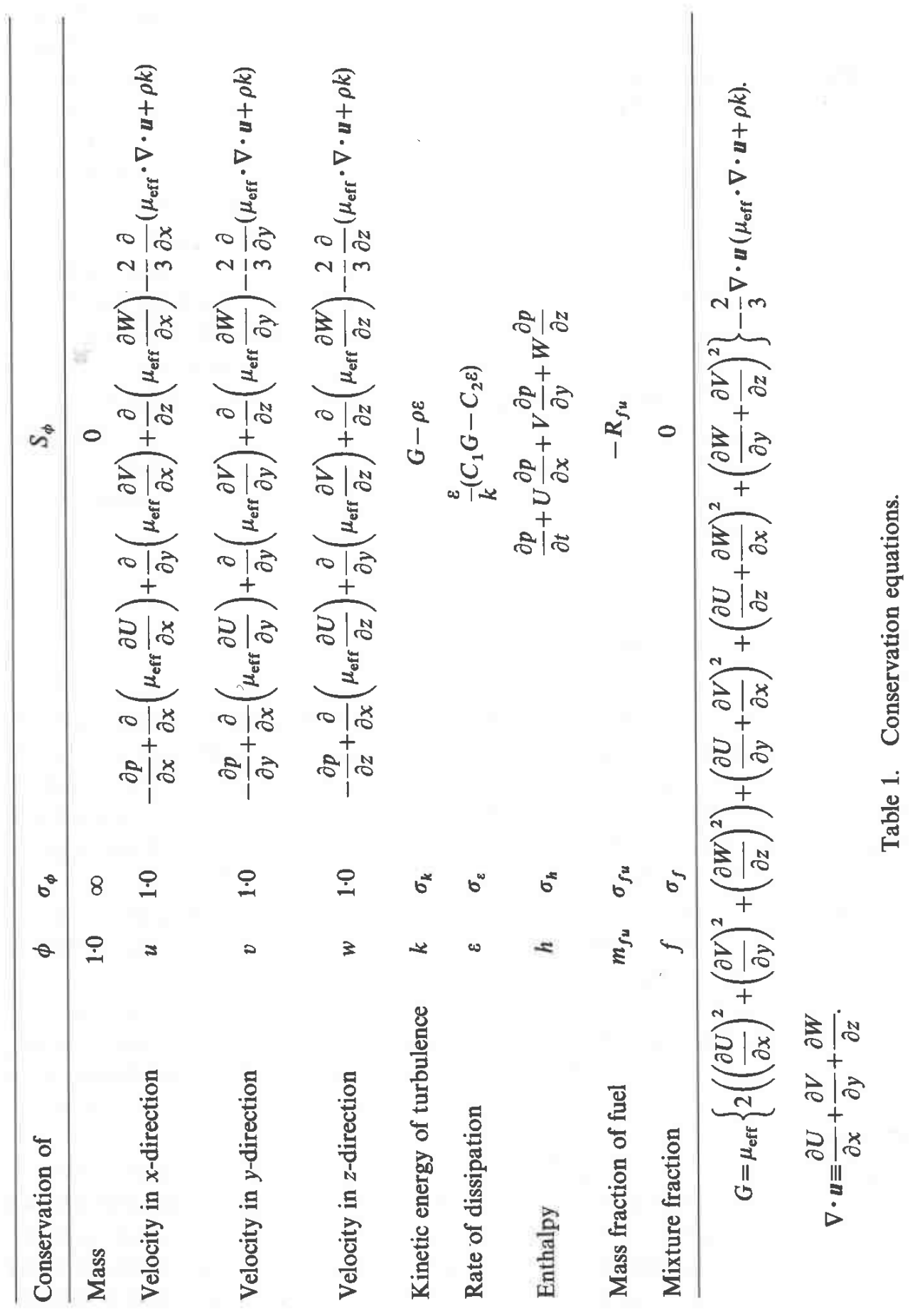


Only a brief description of the solution method adopted by Hjertager (1982 a, b) is given here.

The calculation domain is divided into a finite number of main grid points where pressure $p$, density $\rho$, mass fraction of fuel, $m_{f u}$, mixture fraction $f$, and the two turbulence quantities $k$ and $\varepsilon$ are stored. The three velocity components $U, V$ and $W$ are, on the other hand, stored at grid points located midway between the main points. The conservation equations are integrated over control volumes surrounding the relevant grid points in space, and over a time interval, $\Delta t$. This integration is performed using upwind differencing and implicit formulation.

The result of this is a set of non-linear algebraic equations, which are solved by application of the well known tri-diagonal matrix algorithm used along the three coordinate directions. Special care has been taken to solve the pressure/velocity/density coupling of the three momentum equations and the mass balance. The 'SIMPLE' method developed by Patankar and Spalding (1972) for threedimensional incompressible parabolic flow has been extended by Hjertager (1982 a) to compressible flows and is used to handle this coupling. The method introduces a new variable, the so-called pressure correction which makes the necessary corrections to the velocity components, pressure and density to make them obey the mass balance constraint at the new time level. The pressure correction is determined by solution of a set of algebraic equations derived from the linearized momentum equations and the mass balance equation.

\section{Validation calculations}

\subsection{Tube}

Calculations of flame and pressure development have been performed for three different homogeneous fuel/air mixtures contained in two different $a$ tube geometries.

The methane-air and propane-air data (Moen, Lee, Hjertager, Fuhre and Eckhoff 1982, Hjertager, Fuhre, Parker and Bakke 1984, Hjertager 1984) used are taken from a large-scale explosion study in a $50 \mathrm{~m}^{3}$ tube of $2.5 \mathrm{~m}$ diameter and $10 \mathrm{~m}$ length with 5 orifice rings with variable blockage ratios.

The hydrogen/air data used are taken from a small-scale experimental study performed by Lee, Knystautas and Freiman (1984). This geometry was a tube, $5 \mathrm{~cm}$ in diameter and $3 \mathrm{~m}$ in length, having orifice rings which blocked off $60 \%$ of the free tube area and with distance between rings of $5 \mathrm{~cm}$. These tests comprise a fairly large span in both scale and fuel type and are thus suited for our present validation needs.

The chemical times are taken from Burcat, Crossley and Scheller (1972) and Schott and Kinsey (1958) and the relevant parameters used in expression (23) are compiled in table 2.

Figure 1 shows a comparison between experiments and predictions of peak pressures versus blockage ratio $\left(B . R .=\left(1-(d / D)^{2}\right)\right.$ for methane-air and propane-air mixtures. The figure shows that the large difference in peak pressures between methane-air and propane-air explosions is fairly well predicted. The present prediction method also gives the correct behaviour of pressure versus blockage ratio. There are, however, some underpredictions for propane-air at blockage ratio 0.5 . It should also be mentioned that the original combustion rate model (Magnussen and Hjertager 1976) would only show a 20 per cent difference between methane and propane. This clearly demonstrates that only changes in thermodynamic properties 


\begin{tabular}{lccccl}
\hline Fuel & $A_{c h}$ & $a$ & $b$ & $E / R$ & Reference \\
\hline Methane & $3.6210^{-14}$ & 0.33 & -1.03 & 23.300 & $\begin{array}{c}\text { Burcat, Crossley } \\
\text { and Scheller (1972) and } \\
\text { Schott and Kinsey (1958 }\end{array}$ \\
Propane & $4.4010^{-14}$ & 0.57 & -1.22 & 21.210 & $\begin{array}{c}\text { Burcat, Crossley } \\
\text { Scheller (1972) and } \\
\text { Schott and Kinsey (1958) } \\
\text { Schott and Kinsey (1958) }\end{array}$ \\
\hline Hydrogen & $2.2510^{-11}$ & 0 & -1.0 & 9.132 & \begin{tabular}{c} 
Schot and \\
\hline
\end{tabular}
\end{tabular}

Table 2. Parameters in chemical time formula.

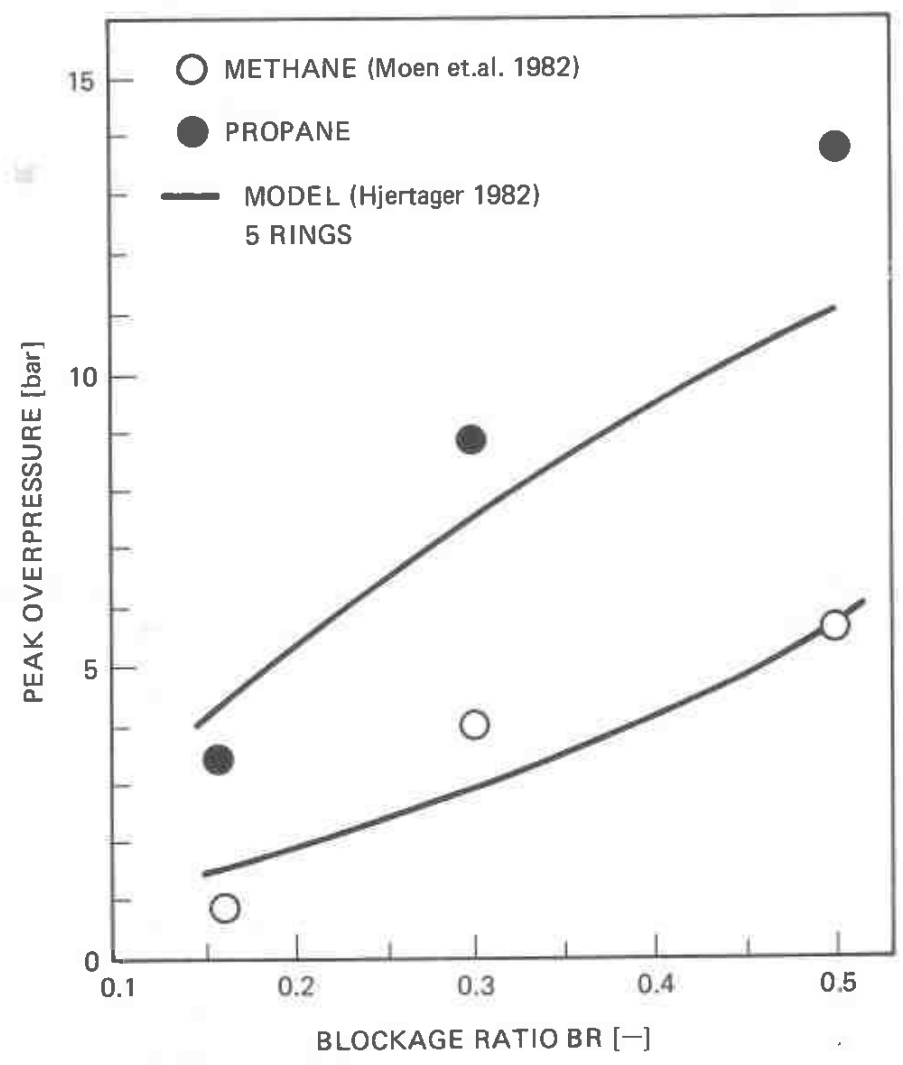

Figure 1. Peak measured (Moen, Lee, Hjertager, Fuhre and Eckhoff 1982, Hjertager, Fuhre, Parker and Bakke 1984) and predicted pressures in the $50 \mathrm{~m}^{3}$ combustion tube as function of blockage ratio, B.R. $=1-(d / D)$ (Hjertager 1982 b). Propane-air and methane-air mixtures.

and the infinite chemical kinetics assumption are not capable of reproducing the experimental differences between methane-air and propane-air explosions.

Figure 2 shows a comparison between the computation model and the experiments of the terminal flame speed for propane-air as function of blockage ratio. It is seen that the agreement is satisfactory and that the model predicts the optimum flame speed at a blockage ratio equals approximately 0.4 .

Figures 3 and 4 show a comparison between predicted and measured peak pressures for variable concentrations of methane-air and propane-air explosions in the 


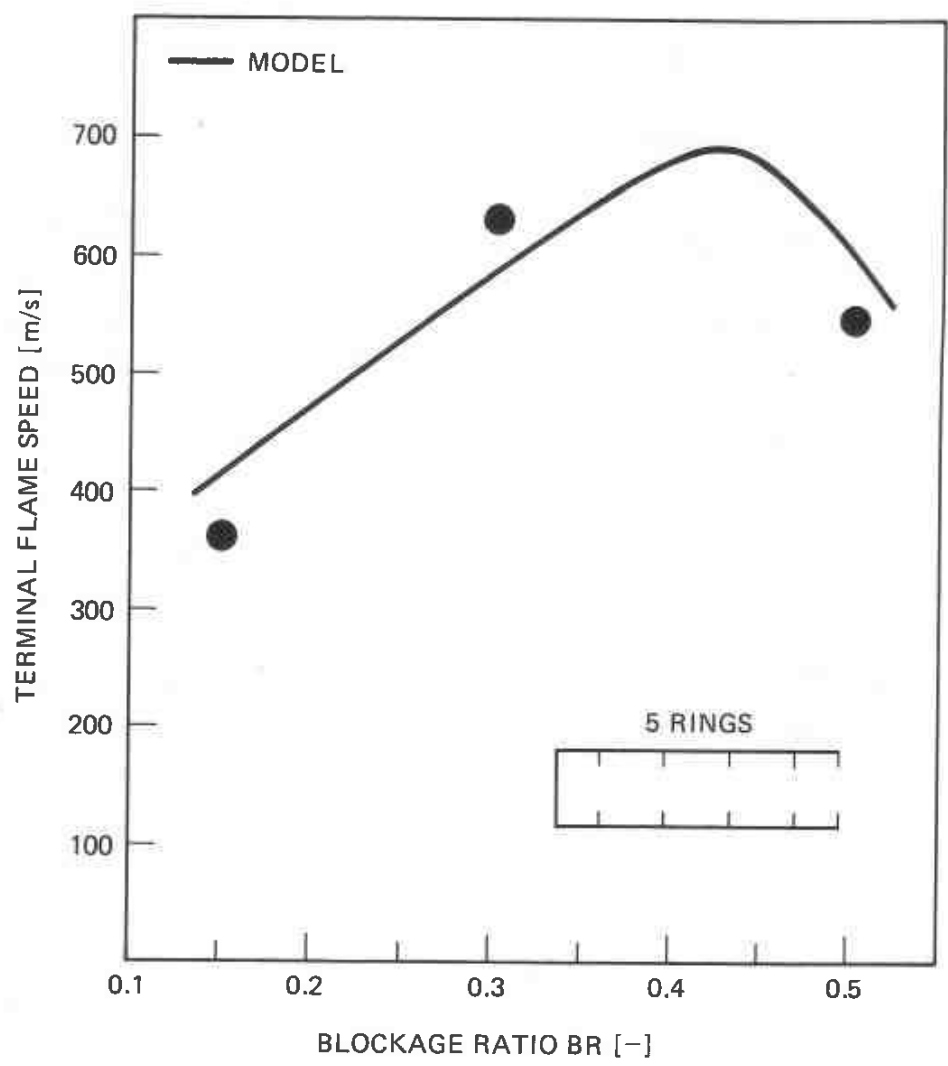

Figure 2. Comparison between measured (Hjertager, Fuhre, Parker and Bakke 1984) and predicted variations of terminal flame speed with blockage ratio.

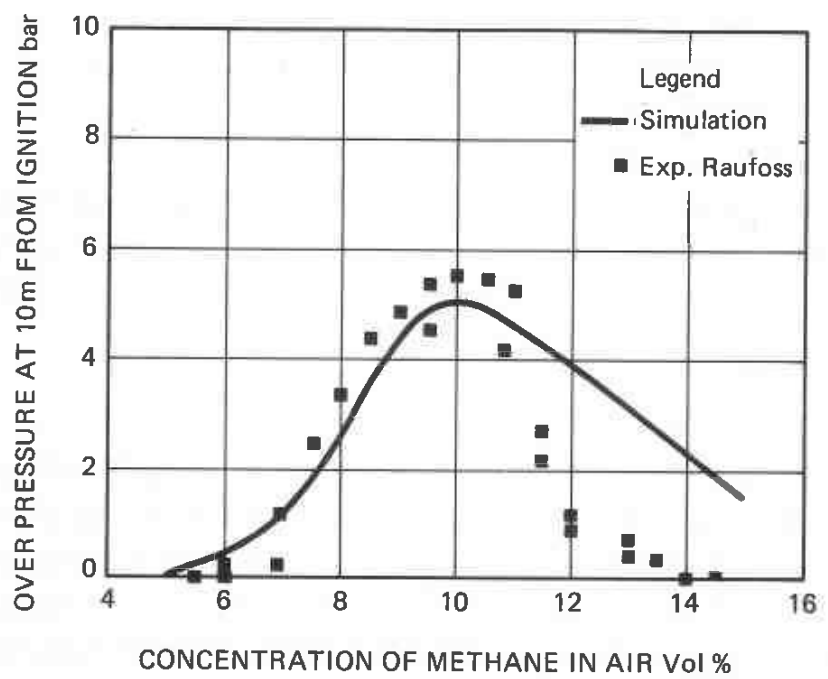

Figure 3. Comparison of measured (Hjertager 1984) and predicted peak overpressures at the exit of the $50 \mathrm{~m}^{3}$ tube versus concentration of methane. 


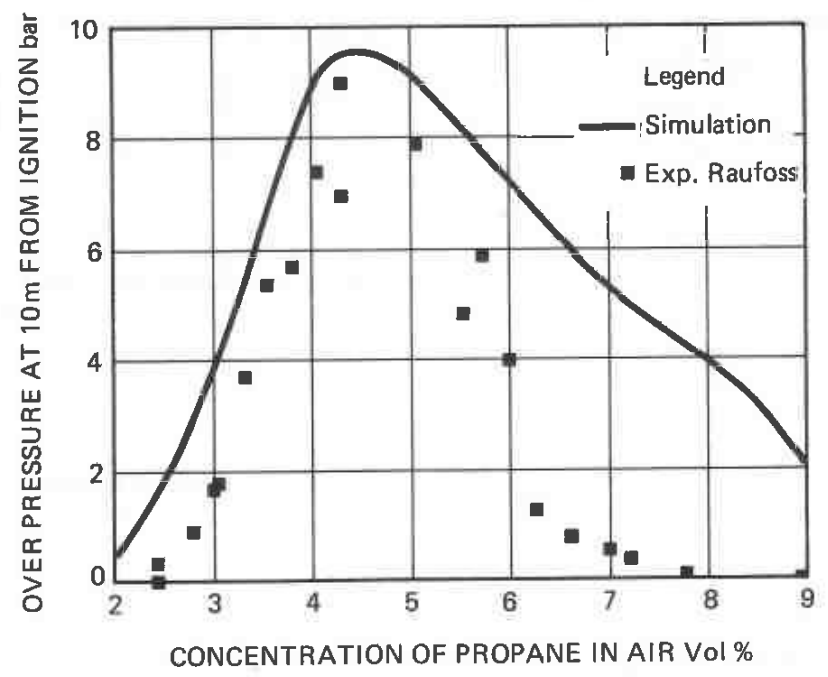

Figure 4. Comparison of measured (Hjertager 1984) and predicted peak overpressures at the exit of the $50 \mathrm{~m}^{3}$ tube versus concentration of propane.

$50 \mathrm{~m}^{3}$ tube. Good agreement between predictions and experiments can be observed for the lean mixtures of methane-air and propane-air, whereas less agreement is seen for both gases at the rich side of stoichiometry. There are good correspondence between measured and predicted concentration for optimum pressure build-up. Both mixtures exhibit this maximum at slightly rich mixtures. This is the same trend as found in detonation sensitivity studies in both methane-air and propane-air mixtures (Bull 1979). The predicted maximum peak pressures are approximately 5 bar for methane and 9.5 bar for propane. This difference has come about mainly because of different reaction times. Figures 5 and 6 elucidate this in more detail. These figures show local distributions within the tube of velocity, flame contours and reaction rate contours for both fuels. In Figs $5(a)$ and $(b)$ the conditions after the flame has passed the first obstacle are shown. We can see that the local distribution of all variables are almost identical for both gases. However, in Figs $6(a)$ and $(b)$, which show the situation after the flame has propagated over the second obstacle, some differences can be observed. At this position of the flame the turbulent mixing time, $\tau_{e}$, has diminished to a value which corresponds to quenching in some regions where the shear in the flow is large. Obviously, as seen in Fig. 6, this quenching is most pronounced for the methane-air mixture, since the chemical induction time is much larger for methane compared to propane. The arrows in Fig 6(b), indicate the extinction region of the methane-air flame. This difference in flame propagation between methane and propane continues also for the rest of the flame travel. The net result of this is as shown in Figs 3 and 4 that the pressures produced in methane-air explosions are lower by a factor of approximately 2 compared to propane-air explosions for identical geometries.

In Figs 7 and 8 are shown comparisons between predictions and measurements of flame speed and pressure produced in different hydrogen/air mixtures. It is seen that the agreement is in general good. The overall behaviour is well predicted for both quantities. However, if we look at the details, there are some discrepancies. These are especially notable close to stoichiometry where the experimental data show a sudden jump to a quasi-detonation. This is not seen in the corresponding predictions. Also, the experimentally observed jump in flame speed close to $13 \%$ hydrogen concentration is 

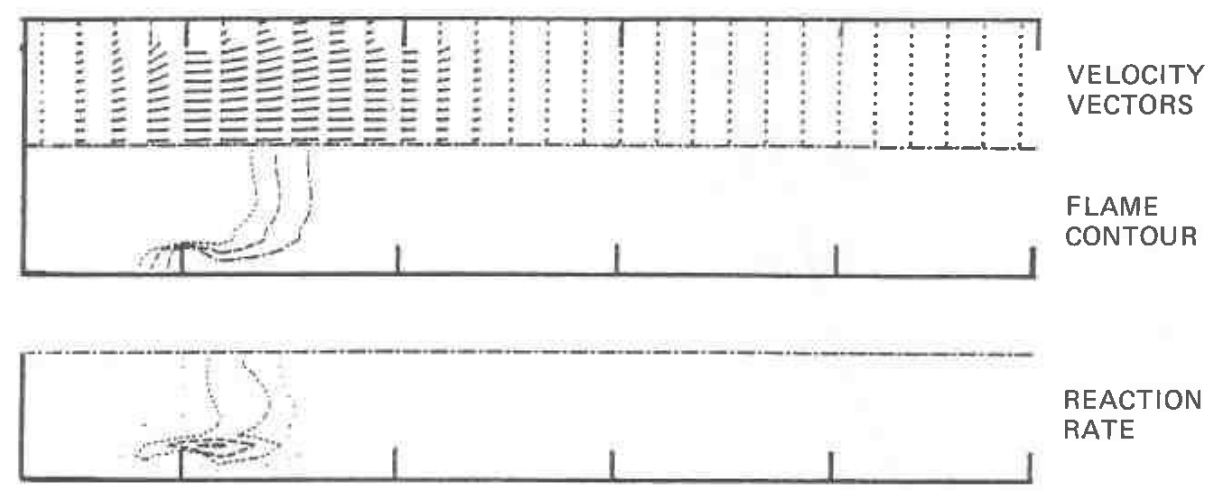

(a)

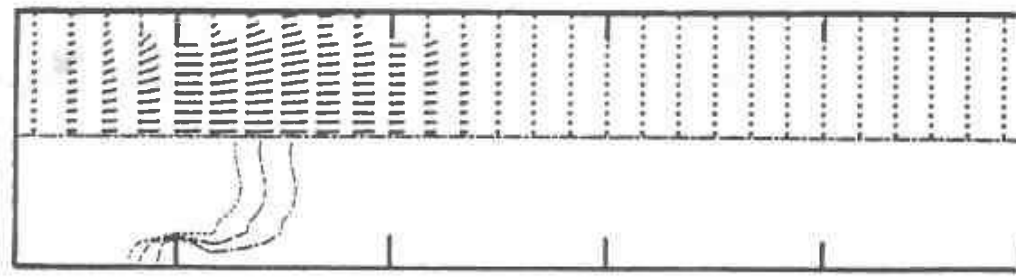

VELOCITY VECTORS

FLAME CONTOURS

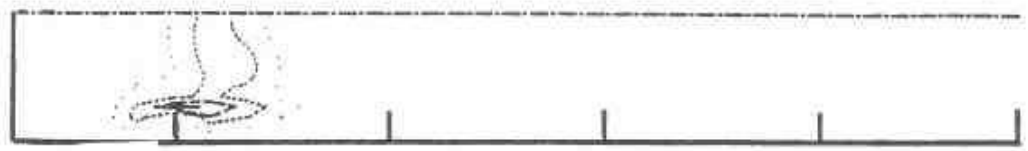

REACTION RATE

(b)

Figure 5. Distribution of velocity, flame and reaction rate for $(a)$ propane-air and $(b)$ methaneair 6 plosions after the flame has passed the first obstacle.

not well predicted. However, the predicted curve in Fig. 7 gives a good indication of the trend. As noted by Lee, Knystautas and Freiman (1984) the sudden jump in flame speed in Fig. 7 is probably due to a sudden change in reaction times. In order to model this correctly, a much more detailed reaction kinetic scheme than the simple induction time formula presently used, would be required.

\subsection{Vented channel}

As can be seen from the previous flame propagation in confined tubes produces high flame speeds and pressures. Chan, Moen and Lee (1983) have performed a small scale study in which they investigated the influence of variable venting in a channel along the propagation path. The layout of their channel is shown in Fig. 9. The length of the channel was $1.22 \mathrm{~m}$ and the height was $0.203 \mathrm{~m}$ with sharp edged repeated obstacles which block off approximately $25 \%$ of the free channel area. The experiments were performed using a homogeneous stoichiometric mixture of methane in air. They found that the flame speed was drastically reduced by reducing the top confinement. This is shown in Fig. $10 \mathrm{a}$. Bakke and Hjertager (1986) used these data in a validation study of the model presented above. Figure 10 shows a comparison between the measured and predicted variation of flame speed versus degree of confinement. The figure shows that there is a close agreement between predictions and experiments. Both the decrease in 

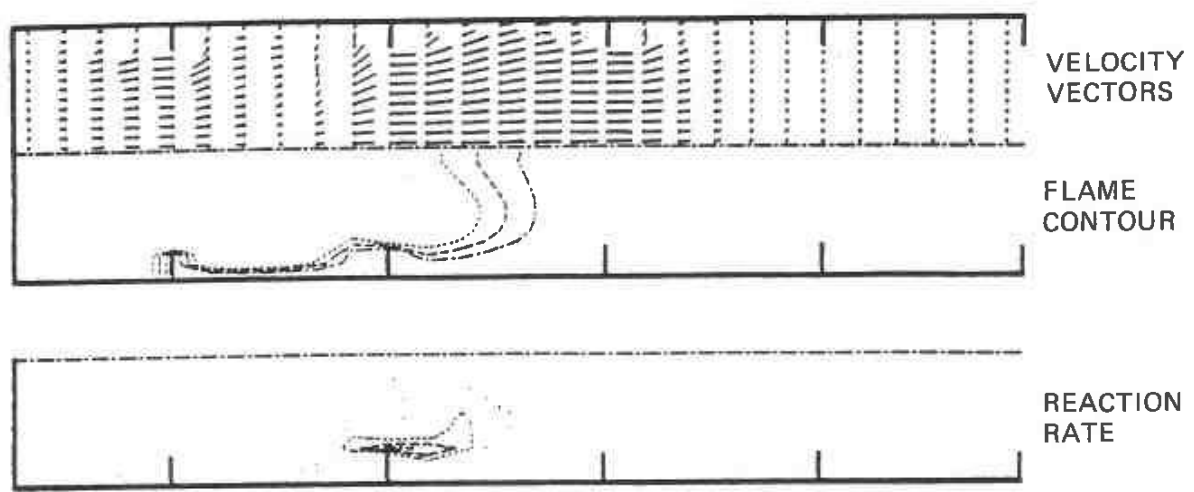

(a)

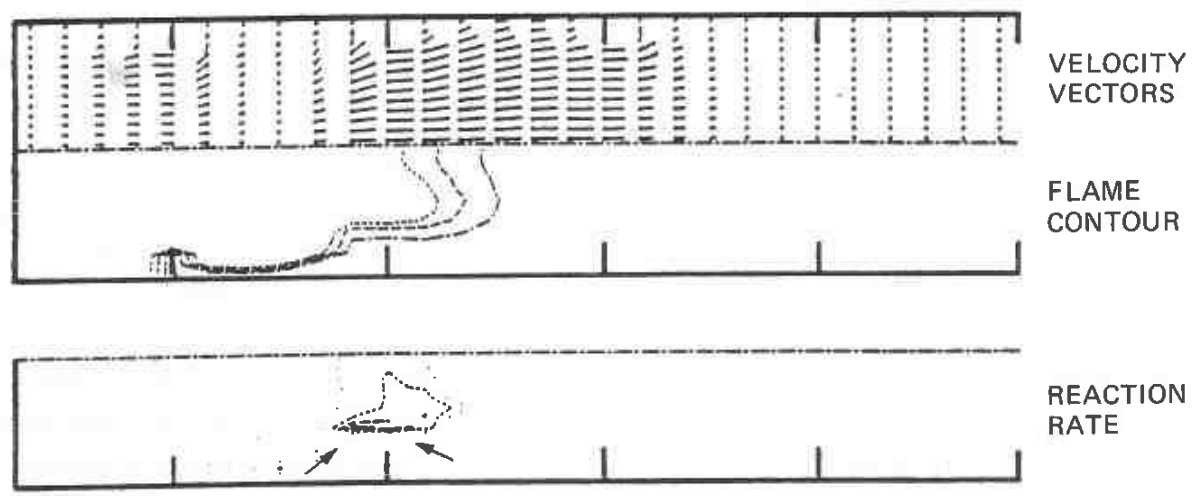

(b)

Figure 6. Distribution of velocity, flame and reaction rate for (a) propane-air and $(b)$ methaneair explosions after the flame has passed the second obstacle. Arrows indicate quenched regions.

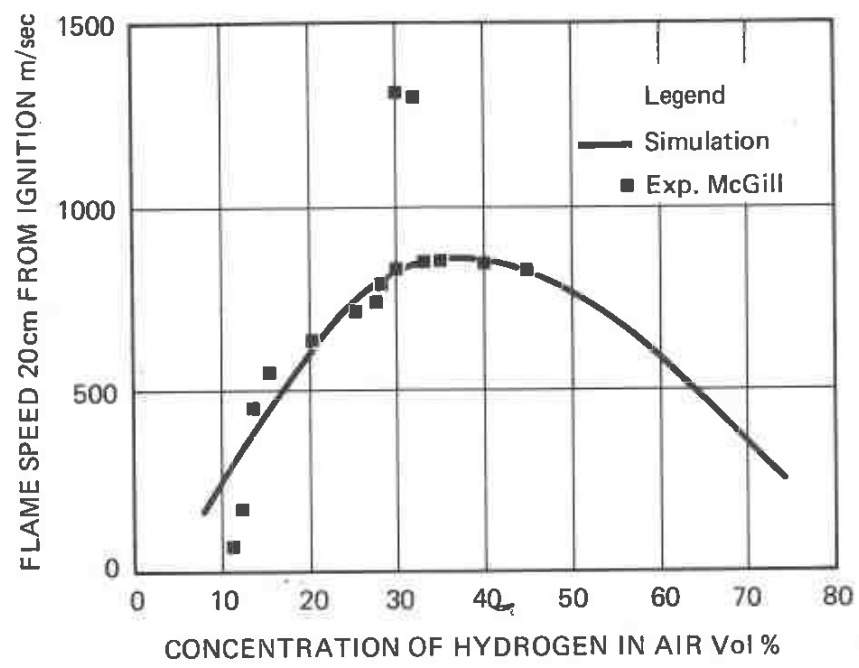

Figure 7. Comparison of measured (Lee, Knystautas and Freiman (1984)) and predicted flame speeds at $20 \mathrm{~cm}$ from ignition as function of hydrogen concentration. 


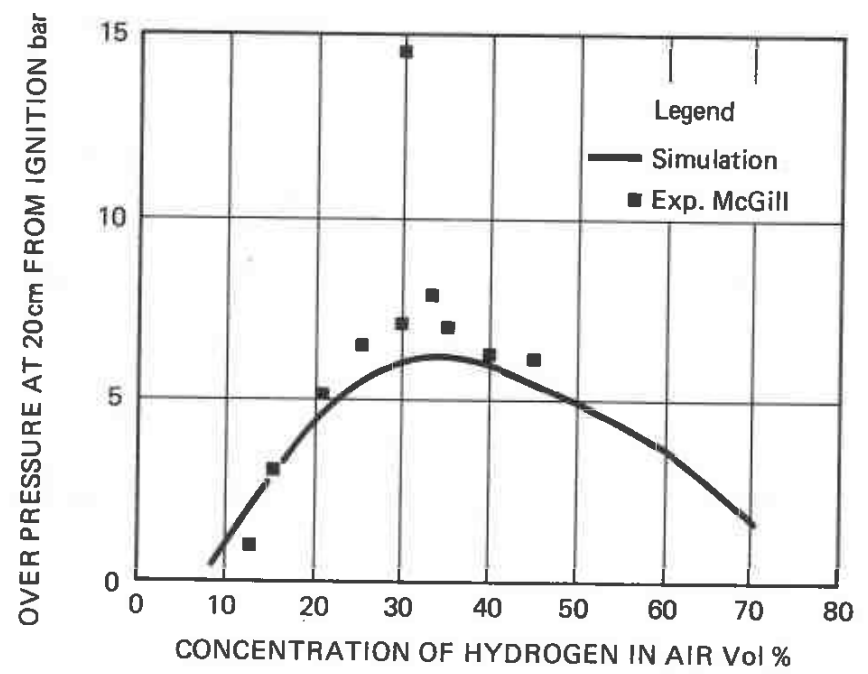

Figure 8. Comparison of measured (Lee, Knystautas and Freiman (1984)) and predicted peak overpressures at $20 \mathrm{~cm}$ from ignition as function of hydrogen concentration.

flame speed and the difference between obstacles along wall and along centre line are fairly well reproduced. Also shown in Fig. 10 is the influence of moving the obstacles off the wall and off the centre line. Both of these cases show flame speeds in between the two extremes. Figure 11 shows the predicted peak pressures versus confinement. We observe that the maximum pressure of over 3 bars is obtained by placing the obstacles along the centre line, whereas moving the obstacles towards the wall reduced the pressures by a factor of 10 in this particular geometry. This shows that the maximum effectiveness of two shear layers are only obtained when the obstacles are exactly in the centre line. Figure 12 shows the predicted distribution of flow velocities, flame contours and pressure contours for these two situations.

Moen, Sulmistras, Hjertager and Bakke (1986) have reported results from largescale tests performed in a top-vented channel of $1.8 \mathrm{~m} \times 1.8 \mathrm{~m}$ in cross section and
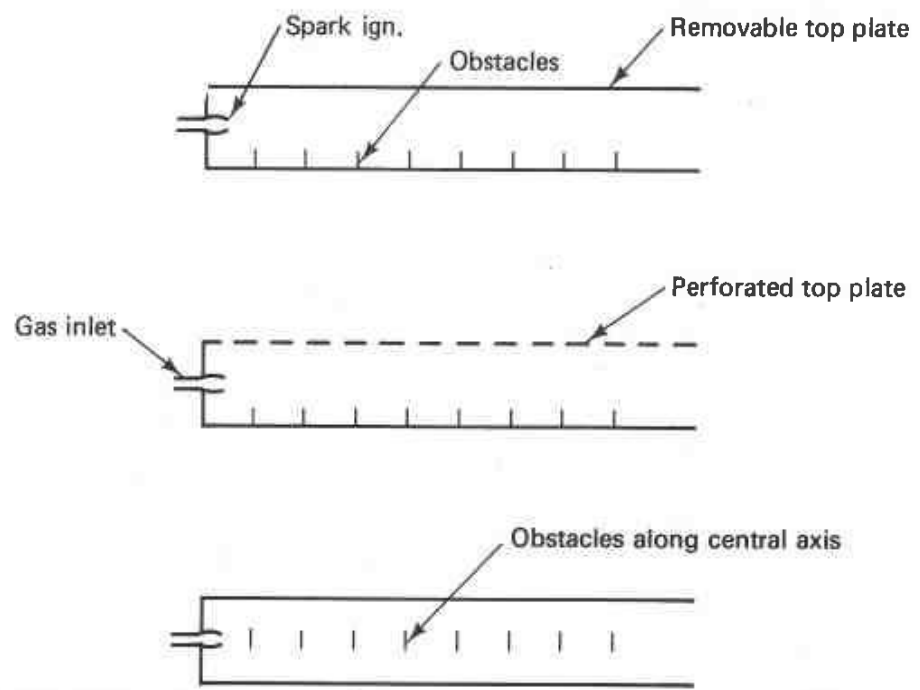

Figure 9. Schematics of experimental apparatus (Chan, Moen and Lee (1983)). 


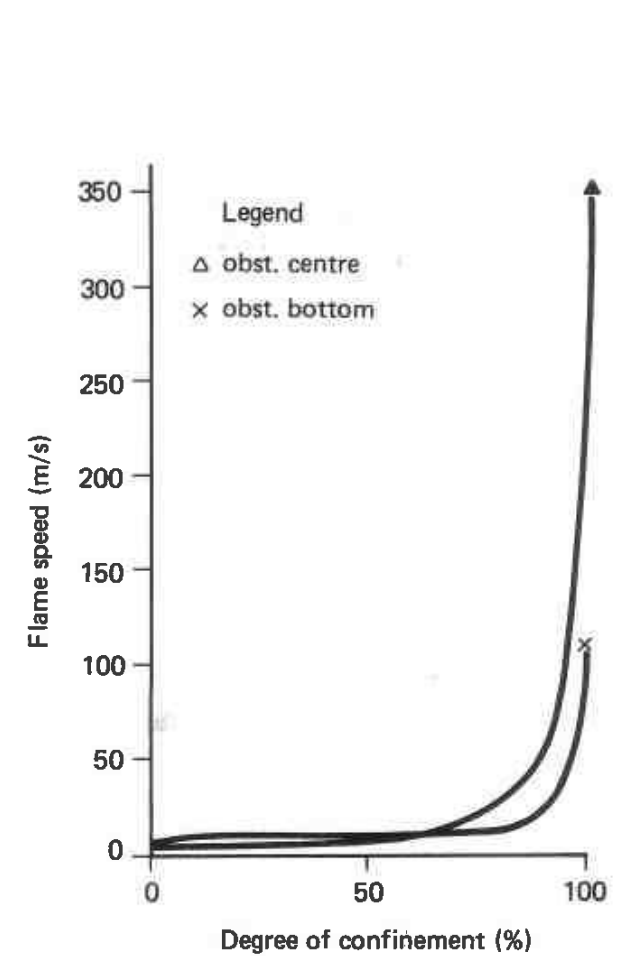

(a)

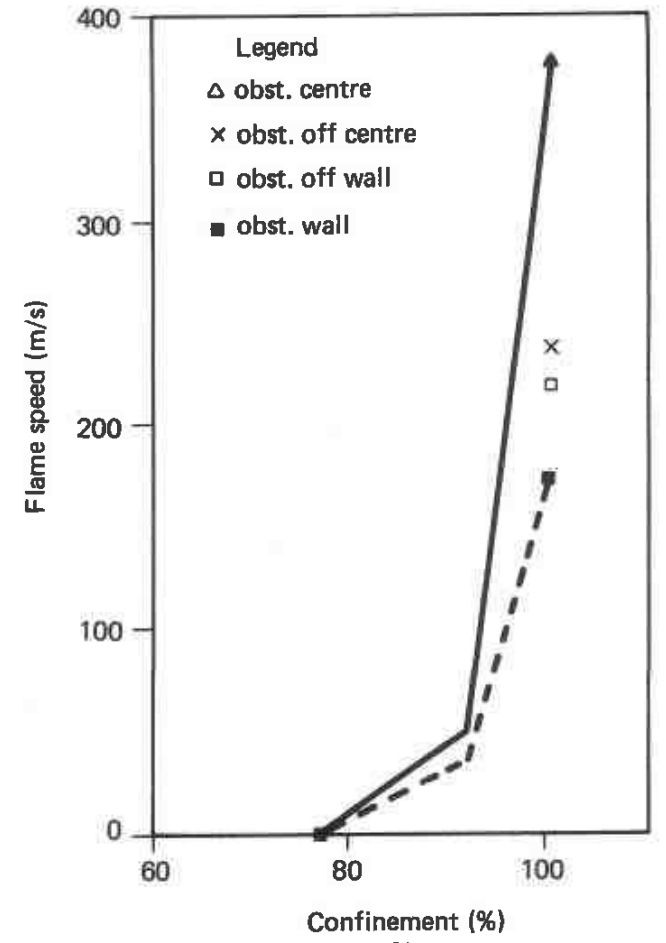

(b)

Figure 10. (a) Measured flame speeds versus confinement. Measured $1 \mathrm{~m}$ from ignition. (Chan, Moen and Lee (1983)). (b) Predicted flame speed versus confinement. Calculated $1 \mathrm{~m}$ from ignition. (Bakke and Hjertager 1986).

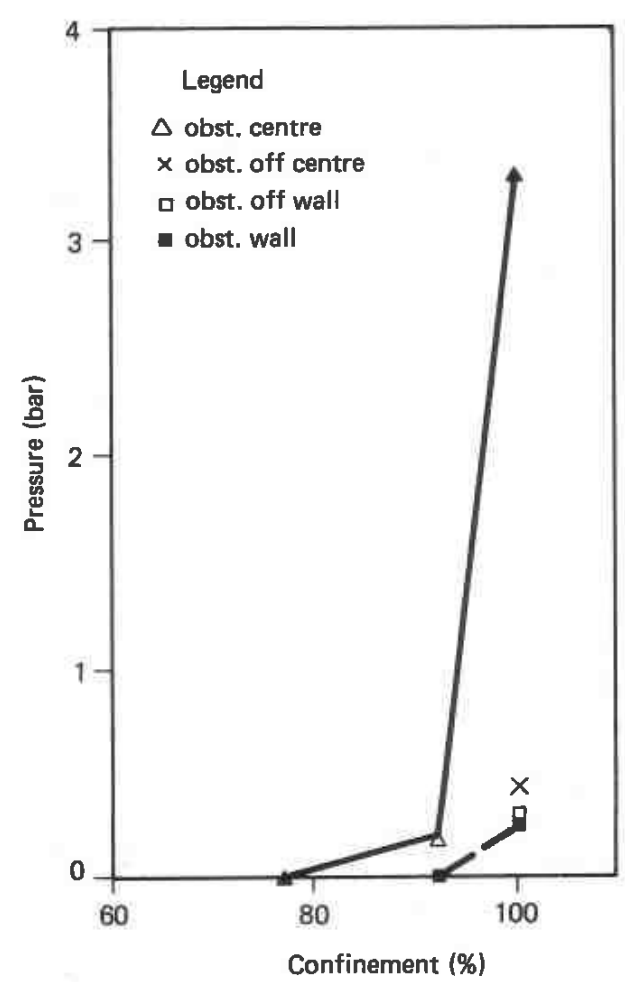

Figure 11. Pressure versus confinement. Monitored near lid and open end; maximum value. (Bakke and Hjertager 1986). 


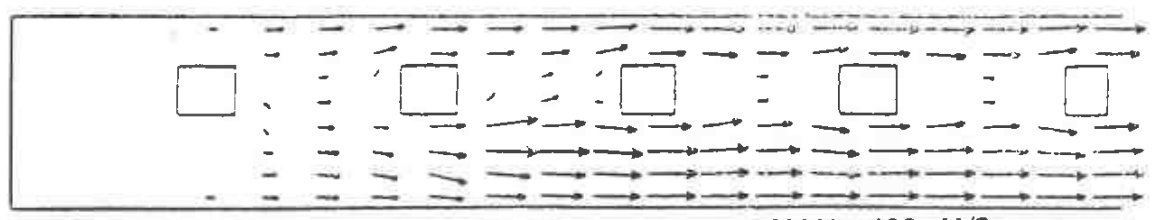

TIME $=8.688 \mathrm{MS}: I T E R=206:$ CPUTIME $=19 . \mathrm{MIN}:$ UMAX $=103 . \mathrm{M} / \mathrm{S}$

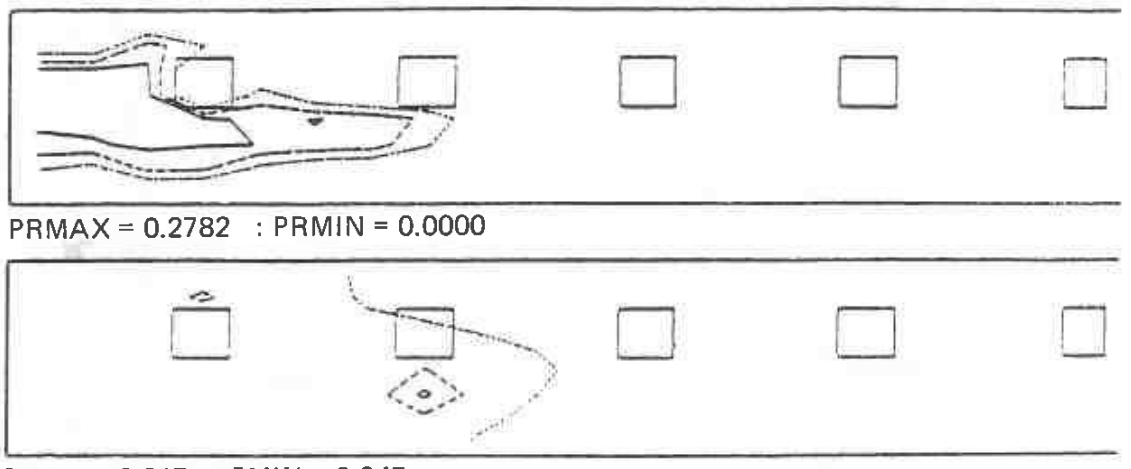

PMAX $=0.317:$ PMIN $=0.045$

Obstacles slightly off-centre line

(a)

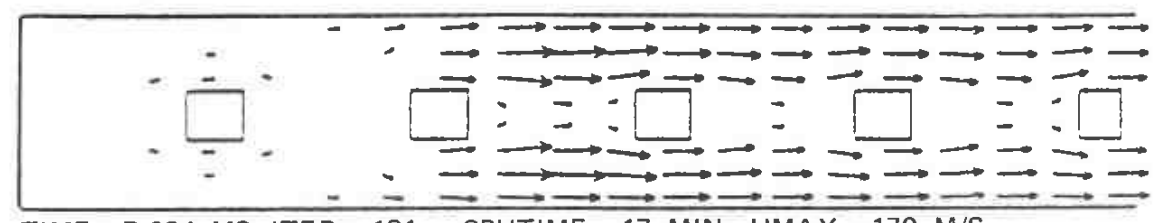

TIME $=7.634 \mathrm{MS}:$ ITER $=181:$ CPUTIME $=17 . \mathrm{MIN}:$ UMAX $=179 . \mathrm{M} / \mathrm{S}$
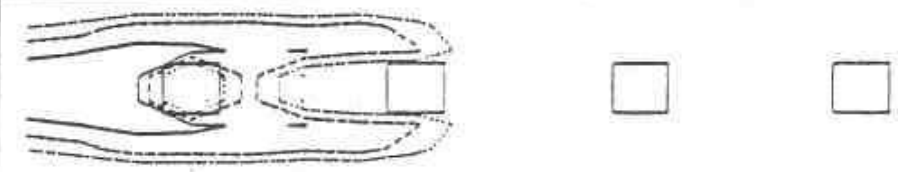

PRMAX $=0.2708 \quad:$ PRMIN $=0.0000$

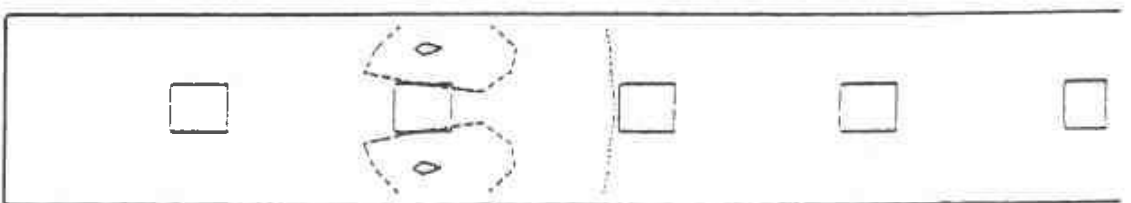

PMAX $=0.928:$ PMIN $=0.152$

Obstacles along centre line

(b)

Figure 12. (a) $-(b)$ Distribution of velocity vectors, flame contours and pressure distribution for $100 \%$ confinement and two different obstacle arrangements. (Bakke and Hjertager 1986.) 
$15.5 \mathrm{~m}$ in length with repeated obstacles. Results are given for three different stoichiometric fuel-air clouds, namely acetylene, propane and hydrogen sulphide. Moen, Sulmistras, Hjertager and Bakke (1986) also include results from application of the FLACS model to some of the experimental tests. The induction time data used in the calculations for acetylene and hydrogen sulphide are given in table 3.

\begin{tabular}{lccccl}
\hline Fuel & Ach & $a$ & $b$ & $E / R$ & Reference \\
\hline Acetylene & $3 \cdot 31 \cdot 10^{-12}$ & 0 & -1.0 & 8.597 & $\begin{array}{l}\text { Kistiakowsky } \\
\text { and Richards (1962) }\end{array}$ \\
$\begin{array}{l}\text { Hydrogen } \\
\text { sulphide }\end{array}$ & $5.0 \cdot 10^{-13}$ & -0.45 & -0.33 & 13.100 & $\begin{array}{c}\text { Frenklach, Lee, White } \\
\text { and Gardiner (1981) }\end{array}$ \\
\hline
\end{tabular}

Table 3. Parameters in chemical time formula.

Calculations are performed for one geometrical layout consisting of obstacles of diameter $0.5 \mathrm{~m}$, pitch equals $1.25 \mathrm{~m}$ and a height above ground of $0.9 \mathrm{~m}$.

Figure 13 shows comparisons between predicted and measured flame speeds along the $15.5 \mathrm{~m}$ length of the obstructed channel. The general characteristics of the observed differences between the three fuels seem to be well predicted. Propane and hydrogen sulphide explosions exhibit much lower flame acceleration compared to acetylene which accelerates to detonation at the end of the channel. The model is not able to predict this sudden transition to detonation due to the fact that only a turbulent combustion model is included.

\subsection{Empty volumes}

All the cases presented above contain internal obstructions inside the volume. Bakke and Hjertager (1987) have applied the FLACS model to the empty volume propane-air tests of Solberg (1982). These tests included three different vessels without obstacles with volumes ranging from 3.6 litres and up to $425 \mathrm{~m}^{3}$.

Figure 14 shows a comparison between predicted and measured variation of the explosion pressure as function of the scaled vent area. As we can see the predictions are in reasonable agreement with measurements for all three volumes.

\section{Scaling characteristics}

This last section will report on some predicted scaling characteristics of fuel-air explosions contained in tubes with length over diameter ratio $L / D=4.0$ and with 5 orifice rings (obstacles) which block off $30 \%$ of the free tube area, and in channels with $L / D=6.0$ and 5 obstacles which block off $25 \%$ of the free channel area. The obstacles are evenly distributed along the enclosure axis from the closed end to the open end, and ignition occurs at the closed end. The tube with a length of $10 \mathrm{~m}$ and diameter of $2.5 \mathrm{~m}$ we take as our base case and define a linear scaling factor of 1.0 for this geometry. If we, for example, increase the length of the geometry to $100 \mathrm{~m}$ and the diameter to $25 \mathrm{~m}$, we have for this situation a linear scaling factor of 10. Explosion calculations have been performed over a range of scaling factors which cover three orders of magnitude, from 0.02 to 50 . This corresponds to lengths of flame propagation from $20 \mathrm{~cm}$ to $500 \mathrm{~m}$. 


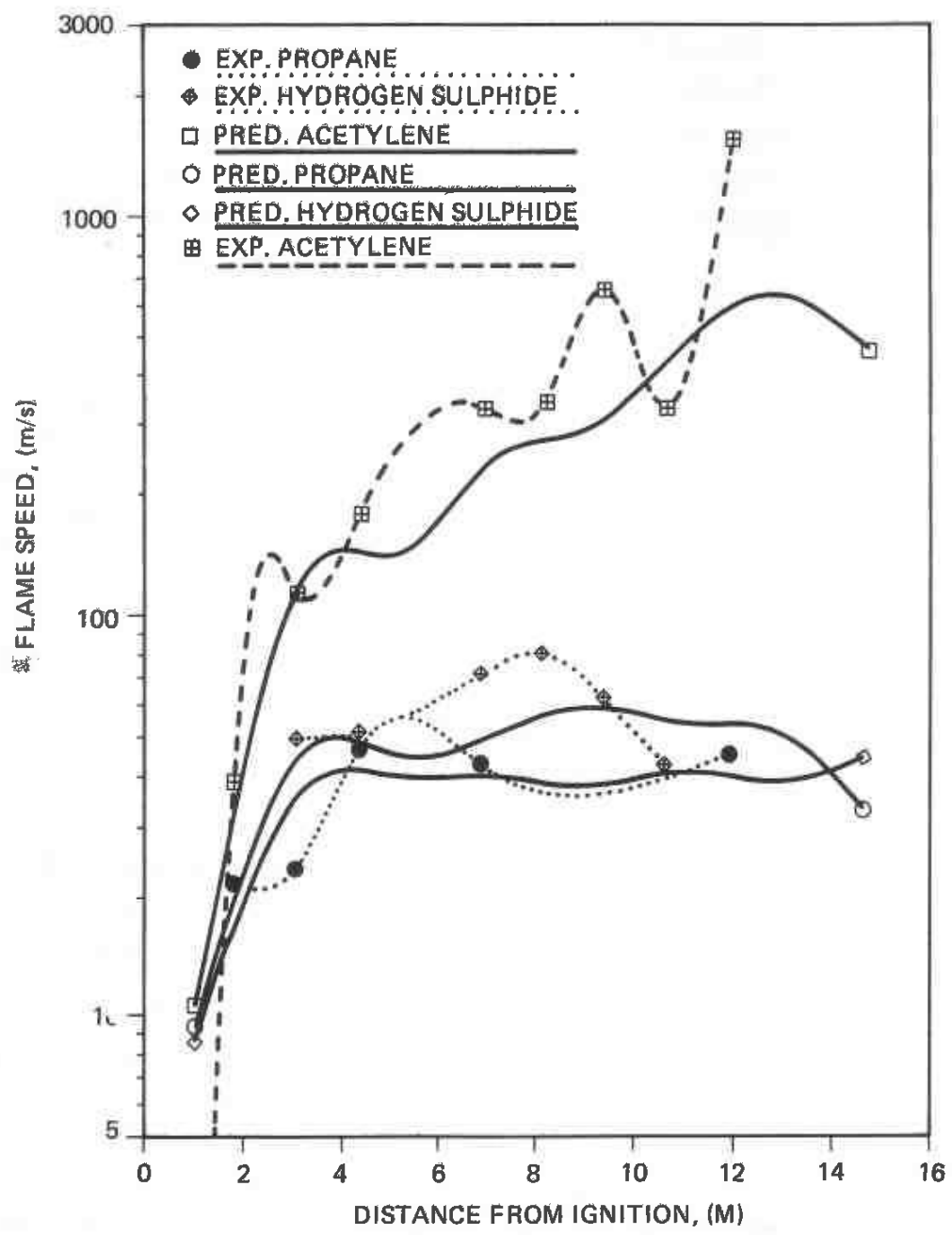

Figure 13. Comparisons of measured and predicted (Moen, Sulmistras, Hjertager and Bakke 1986) flame speeds along the $15.5 \mathrm{~m}$ vented channel.

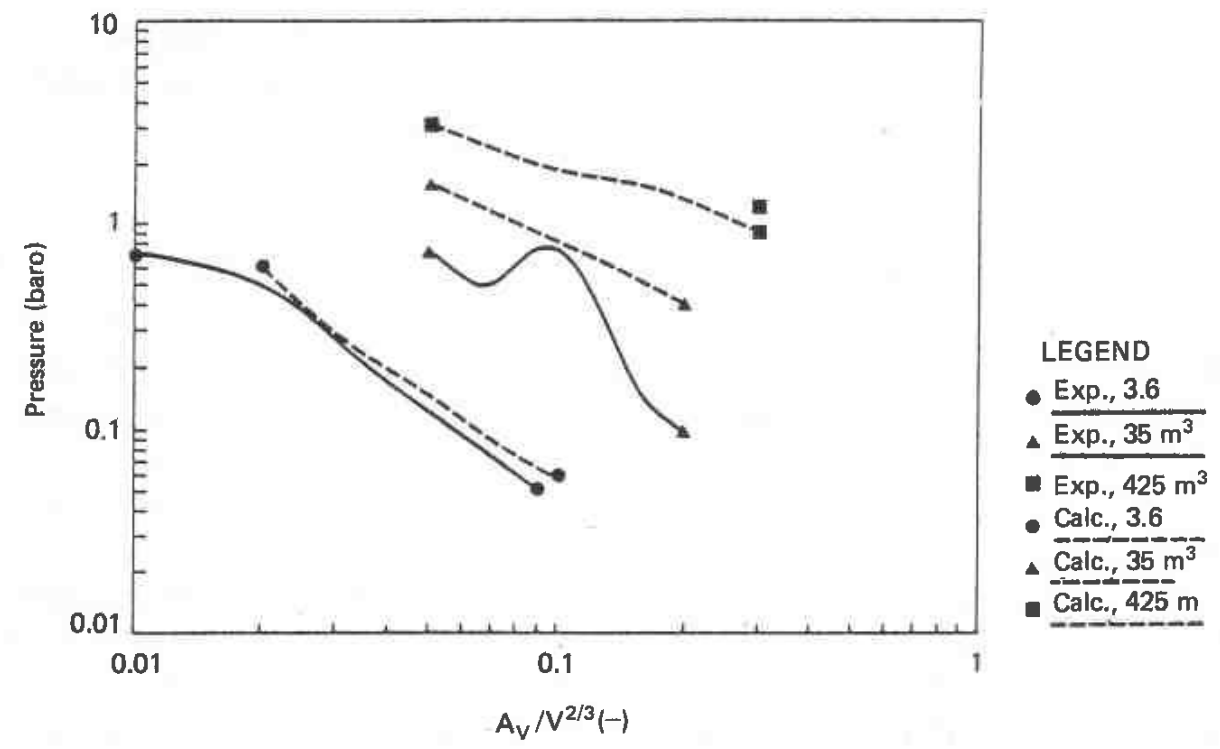

Figure 14. Measured (Solberg 1982) and predicted (Bakke and Hjertager 1985) peak pressures as function of the vent parameter for three different empty vessels. 


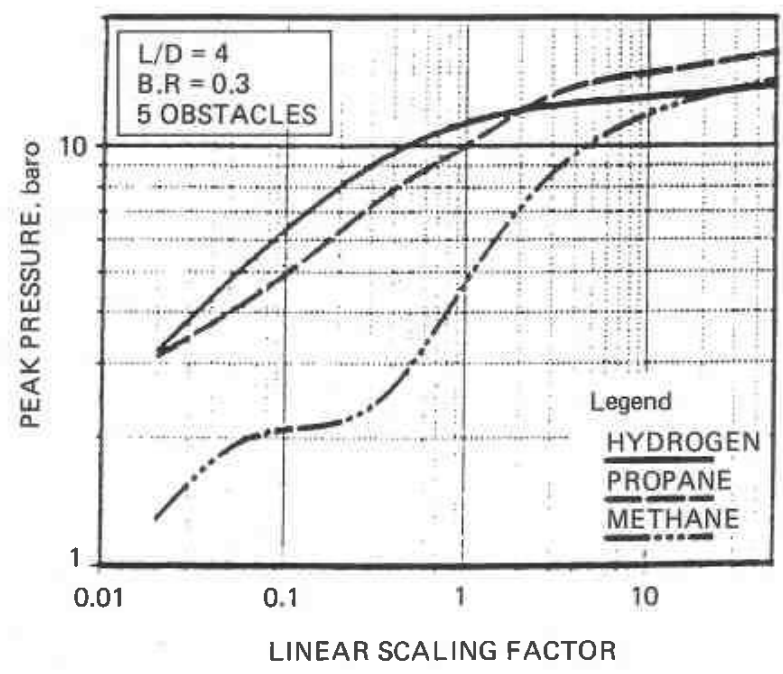

Figure 15. Variation of peak overpressure in stoichiometric mixtures of methane-air, propaneair and hydrogen-air with scaling. Scaling factor of 1.0 indicates $10 \mathrm{~m}$ of flame travel over 5 obstacles.

The channel with length of $1.22 \mathrm{~m}$ and height of $0.203 \mathrm{~m}$ (Chan, Moen and Lee (1983)) we take as the base and define a length scale of 1.0 for this geometry. If for this case we increase the length to $122 \mathrm{~m}$ and the height to $20.3 \mathrm{~m}$ we obtain a scaling factor of 100 .

Figure 15 shows the predicted peak overpressure produced in stoichiometric mixtures of methane-air, propane-air and hydrogen-air as function of the linear scaling factor. It can be seen that all three gases exhibit a strong dependence of peak pressure on scaling. The larger the scale, the higher the explosion pressure. Both hydrogen and propane produce larger pressures than methane. It is observed that the difference in peak pressure ratio between propane and methane in a $0.5 \mathrm{~m}$ tube (linear scaling equals $0 \cdot 05$ ) is $2 \cdot 0$, a value which is in good accordance with the experimental results reported by Hjertager (1984) in a $0.5 \mathrm{~m}$ radial geometry.

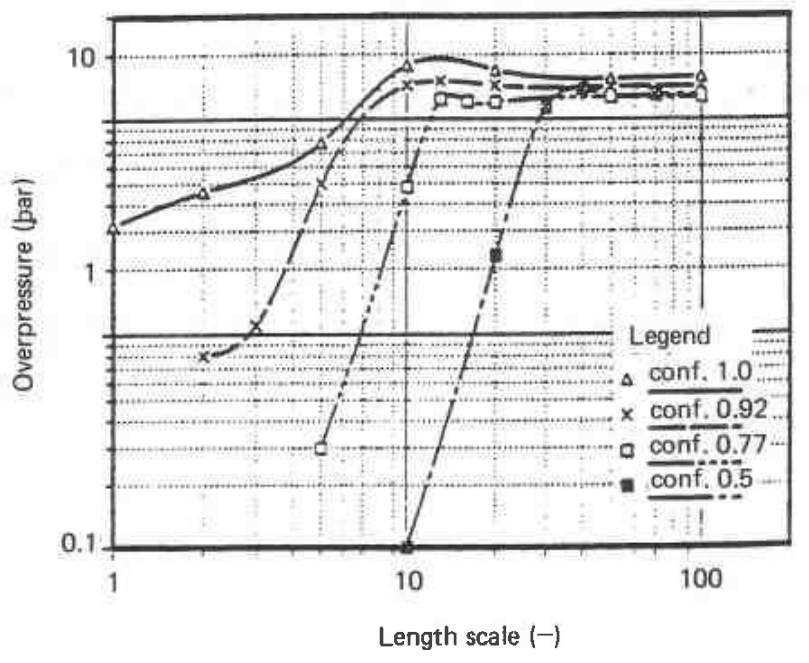

Figure 16. Maximum overpressure versus length scale. Obstacles along central axis of channel. (Bakke and Hjertager 1986.) 
Figure 16 shows the predicted peak overpressure produced by stoichiometric methane-air mixtures in a vented channel as function of length scale. The figure shows that the effectiveness of venting is reduced with increasing scale. For example will a vessel of length approximately $3.6 \mathrm{~m}$ (scale 3 ) and confinement fraction on top wall of $0.92(8 \%$ porosity) produce a pressure of 1 bar. A scale-up of this geometry to a vessel with length of $25 \mathrm{~m}$ (scale 20) would produce a pressure of over 10 bars. In order to reduce the pressure to below 1 bar a confinement fraction of the top wall smaller than $50 \%$ should be chosen (porosity larger than $50 \%$ ). This indicates that larger scales need larger vent areas to reduce the pressure to acceptable values.

\section{Concluding remarks}

A computer model capable of handling the processes which occur in turbulent gas explosions inside complex geometries is presented. The model which is incorporated in the computer code named FLACS is tested against a range of experimental data from a variety of different fuels and geometrical configurations. Comparisons between predicted and experimental results reveal that the model gives reasonable agreement for a range of different cases. Further development and validation of the model should include explosions of non-homogeneous clouds and explosions inside realistic industrial geometries. Because the model does not enable prediction of transition from deflagration to detonation, further work is needed in this particular area.

\section{ACKNOWLEDGMENTS}

The work at Chr. Michelsen Institute on gas explosions has been financially supported by BP Petroleum Development Ltd., Norway, Elf Aquitaine Norge A/S, Esso Norge A/S, Mobil Exploration Norway Inc., Norsk Hydro and Statoil, Norway.

\section{REFERENCES}

BAKKE, J. R. and HJER TAGER, B. H. (1986). The effect of explosion venting in obstructed channels, in Modeling and Simulation in Engineering, B. Wahlström and K. Leiviskä (editors) (Elsevier Science Publication: Amsterdam), pp. 237-241.

BAKKE, J. R. and HJERTAGER, B. H. (1987). The effect of explosion venting in empty vessels, Int. $J$. Numerical Methods in Engineering, 24, 129-140.

Boris, J. P. and BooK, D. L. (1973). Flux-corrected transport I: Shasta-A fluid transport algorithm that works, J. Comp. Phys., 11, 38.

BuLL, D. C. (1979). Concentration limits to the initiation of unconfined detonation in fuel-air mixtures. Trans. l. Chem. E., 57, 219-227.

Burcat, A., Crossley, R. W. and Scheller, K. (1972). Shock tube investigation of ignition in ethane-oxygen-argon mixtures, Combustion and Flame, 18, 115-123.

Chan, C., MoEn, I. O. and LEE, J. H. S. (1983). Influence of confinement on flame acceleration due to repeated obstacles. Combustion and Flame, 49, 27.

Cloutman, L. D., Dukowicz, J. K., Ramshaw, J. D. and Amsden, A. A. (1982). CONCHASSPRAY: A computer code for reactive flows with fuel sprays, Los Alamos National Laboratory Report LA-9294-MS.

Cloutman, L. D., Hirt, C. W. and Romero, N. C. (1976). SOlA-ICE: A numerical solution algorithm for transient compressible fluid flows, Los Alamos Scientific Laboratory Report, LA-6236 (1976).

FrenkLACH, M., LeE, J. H. S., White, J. N. and GARDiner, W. C. (1981). Oxydation of hydrogen sulphide, Combustion and Flame, 41, 1-16.

HJeRTAGER, B. H. (1982a). Simulation of transient compressible turbulent reactive flows, Combustion Science and Technology, 27, 159-170. 
HJERTAGER, B. H. (1982 b). Numerical simulation of turbulent flame and pressure development in gas explosions in Fuel-air explosions, SM Study No. 16 (University of Waterloo Press, Ontario, Canada) pp. 407-426.

HJERTAGER, B. H. (1984). Influence of turbulence on gas explosions. J. Hazardous Materials, 9, 315-346.

HJertager, B. H., Fuhre, K., Parker, S. J. and Bakke, J. R. (1984). Flame acceleration of propane-air in a large-scale obstructed tube. 9th International Colloquium on Dynamics of Explosions and Reactive Systems, Poitiers, France, 3-8 July (1983). Also Prog. AIAA, 94, 504-522.

KISTIAKOWSKY, G. B. and RICHARDS, L. W.(1962). Emission of vacuum ultraviolet radiation from the acetylene-oxygen and the methane-oxygen reactions in shock waves, J. Chem. Phys., 36, 1707.

KJÄLDMAN, L. and HuHTANEN, R. (1986). Numerical simulation of vapour cloud and dust explosions, in Numerical Simulation of Fluid Flow and Heat/Mass Transfer Processes, Vol. 18, Lecture Notes in Engineering, pp. 148-158.

LAUnder, B. E. and Spalding, D. B. (1974). The numerical computation of turbulent flows. Computer Methods in Applied Mechanics and Engineering, No. 3, pp. 269-289.

LeE, J. H. S., Knystautas, R. and Freiman, A. (1924). High speed turbulent deflagrations and transition to detonation in $\mathrm{H}_{2}$-air mixtures, Combustion and Flame, 56, 227-239.

Magnussen, B. F. and HJertager, B. H. (1976). On mathematical modelling of turbulent combustion with special emphasis on soot formation and combustion. 16th Symp., (Int.) on Combustion, Combustion Institute, Pittsburgh, Pa, pp. 719-729.

Martin, D. (1986). Some calculations using the two-dimensional turbulent combustion code FLARE, SRD Report R373, UK Atomic Energy Authority.

MaRx, K. D., LEE, J. H. S. and Cummings, J. C. (1985). Modeling of flame acceleration in tubes with obstables, Proc. of 11th IMACS World Congress on System Simulation and Scientific Computation, Vol. 5, pp. 13-16.

Moen, I. O., LeE, J. H. S., HJertager, B. H., Fuhre, K. and EckhoFf, R. K. (1982). Pressure development due to turbulent flame propagation in large-scale methane-air explosions, Combustion and Flame, 47, 31-52.

Moen, I. O., Sulmistras, A., HJertager, B. H. and BakKe, J. R. (1986). Turbulent flame propagation and transition to detonation in large fuel-air clouds, Presented at the 21 st International Symposium on Combustion, Munich, West Germany, August 3-8.

Patankar, S. V. and Spalding, D. B. (1972). A calculation procedure for heat, mass and momentum transfer in three-dimensional parabolic flows. Int. J. Heat and Mass Transfer, 15, 1787.

Patankar, S. V. and Spalding, D. B. (1974). A calculation procedure for the transient and steady-state behavior of shell-and-tube heat exchangers in Heat Exchangers: Design and Theory Sourcebook, edited by N. H. Afgan and E. V. Schlünder (McGraw-Hill), pp. 155176.

SCHOTT, G. L. and KINSEY, J. L. (1958). Kinetic studies of hydroxyl radicals in shock waves. II. induction times in the hydrogen-oxygen reaction. J. Chemical Physics, 29, 1177-1182.

SHA, W. T. and LAUNDER, B. E. (1979). A model for turbulent momentum and heat transport in large rod bundles, ANL-77-73.

Sha, W. T., YANG, C. I., KAO, T. T. and Cho, S. M. (1982). Multi-dimensional numerical modelling of heat exchangers, Journal of Heat Transfer, 104, 417-425.

SOlbERG, D. M. (1982). Gas Explosion Research Related to Safety of Ships and Offshore Platforms, Fuel-Air Explosions, SM Study No. 16 (Univ. of Waterloo Press, Ontario, Canada), pp. 787-819.

SPALDING, D. B. (1981). A general purpose computer program for multi-dimensional one- and two-phase flow, Mathematics and Computers in Simulation, IMACS, XXII, pp. 267-276. 